\title{
The Effect of Teaching a Sports and Health Course on the Attitudes of the Hashemite University Students towards Certain Healthy Food Habits and Physical Activities Practice
}

\author{
A. Al Haliq Mahmoud \\ Coaching and Sport Management, \\ Faculty of Physical Education and Sport Sciences, \\ The Hashemite University, \\ P.O Box 330127, Zarqa 13133, Jordan

\section{A. Oudat Mo'een} \\ Sport Rehabilitation, \\ Faculty of Physical Education and Sport Sciences, \\ The Hashemite University, \\ P.O Box 330127, Zarqa 13133, Jordan
}

DOI: https://doi.org/10.36941/jesr-2022-0052

\section{Abstract}

This study aimed at identifying the effect of teaching a sports and health course on the Hashemite University students' attitudes towards certain food habits and the practice of physical activities. The study sample consisted of (100) male and female students, who are enrolled in the sports and health course in the first semester of the academic year 2020/2021. The instrument of Saleh and Al-Ahmadi (2016) was used for our study, which included (40) items distributed over two domains (healthy eating habits and physical activities practice). The scientific coefficients of the study instrument were calculated, and the total reliability coefficient amounted (o.91), as well as the means (M's) and standard deviations (SD's). Furthermore, the Test-Retest and MANOVA procedures were applied to identify the differences among the means and to answer the study questions. The results showed statistically significant differences between the pretest and posttest scores, which were in favor of the posttest. In addition, there were differences in the means of all the domains and the instrument, as a whole, between the pretest and posttest, which are ascribed to the gender variable, in favor of the females in the healthy eating habits domain, and in favor of males in the physical activities practice. The results further showed differences among the means in all the domains and the instrument, as a whole, between the pretest and posttest attributed to the college variable, in favor of the humane science colleges. Moreover, there were differences among the means in all the domains and the instrument, as a whole, between the pretest and posttest ascribed to the academic year variable, which were in favor of the first year in the physical activities practice domain. In the light of these results, the researcher concluded that teaching a "sports and health" course, with its concepts and information, has a positive effect in changing the students' attitudes towards the healthy eating habits and physical activities practice. The researcher recommended that this course should be introduced as a compulsory course for all the university students.

Keywords: Healthy eating habits, physical activities, the Hashemite University 


\section{Introduction}

Views of the recent age agree on the importance of the sound, healthy eating habits and physical activity, and their effects on achieving all whatever better for the public health. But, what is spreading out in our age among many people of certain improper eating and food behaviors and motor lethargy, led eventually to bring the human health to what is currently termed "hypokinetic diseases" (Maghayreh and Ahmad, 2011; Al-Smadi and Al-Harithy, 2017).

Health is considered the relative equilibrium state of the functions of the body organs, which result from a person's adaptation to his daily behaviors and overcoming the harmful, unhealthy factors and habits that he may experience. The issue of the healthy behavior and its development gained wide importance, as there is a relationship, which should be discovered, between behavior and health that led to great changes in the last three decades of the past century in the promotion of the health level, and potential to influence at the community level. Therefore, it is necessary to work to educate community members about the importance of health culture, healthy behavior, and the practice of physical activities, starting with awareness about these aspects. This means their knowledge of the health information and facts, and their sense of responsibility towards their health and the health of others. In this regard, culture is theoretical information, while awareness is the practice of the behaviors as a result of understanding and convictions (Jwaihan and Arjan, 2018).

The awareness that many people are lacking nowadays, in its different and multiple forms and patterns, led to limit their food meals to a few types of foods, ignoring the nutritious values that are found in many foods and other nutrients, as well as their health benefits. The World Health Organization (WHO) repeatedly announces that the physical activity, beside the sound healthy nutrition, have a large role in improving the general health of the body, and protection from many diseases. A report of the WHO, Geneva provided that the diet and physical activity, jointly or severally, equally, have an effect on the general health; that there is a close link between the physical activity and individuals' general health; and, that the healthy life style requires sound and healthy nutrition, practice of physical activity, and avoiding unhealthy habits (Mash'al et al, 2012; Sofi et al, 2008).

In the Hashemite Kingdom of Jordan, which witnessed a civilized development during the past few decades, the community lives noticeable changes in the life style, eating habits, and sports habits. The physical activity decreased significantly, which made the life sedentary, and lack of movement has become one of the Jordanian community features nowadays. Governments as well as the private sectors demand enacting legislations that encourage the practice of physical activities. Documents issued by the Jordanian Ministry of Health in 2019 indicate that the expenditures on health was 8.9\% of the GNP; that the death causes related to the circulatory system (cardiovascular) diseases in 2015 comprised $39.14 \%$ of the total patients; and that the iron deficiency among the Jordanian women, who are in childbearing age, reached $19.8 \%$ in 2016 (Ministry of Health, 2019).

Many sports researchers (Al-Jabali, 2018; Al-Shafi'e, 2010; Al-Zo'bi et al, 2020; Yalcin et al, 2020), indicate that the best ways to understand the individuals' behaviors in terms of physical activity practice is to identify their trends and motives towards participation in the activity. Positive trends towards practice of physical activities define the active life style the people live. Therefore, if the individual has positive trends towards practice of physical activities and following the healthy diet, then the behavior he shows reflects these trends.

University students' practice of physical activities is among the most important factors to enjoy good health and a suitable level of body fitness (Sogari et al, 2018 \& Ruiz et al, 2017). In addition, following a healthy diet and practice of moderate intensity physical activities have positive effects on the different body functions. While, on the contrary, physical inactivity and lack of a healthy diet lead to a pool of negative effects on both the individual's and community health (Koehler \& Drenowatz, 2019).

The significance of this study lies in revealing the students' trends towards the healthy eating habits and practice of physical activities. It also dealt in the relationships between the trends and the 
selected variables, which increase the knowledge that we can rely on with confidence when planning in the university, to coincide with trends in the students' interests and tendencies. Moreover, the results of the current study will enable identifying the nature of these trends to take the procedures that develop the positive trends, and deal with the negative trends, amend or change them. The students' positive trends have an important role towards the healthy eating habits and physical activities practice. They strongly influence guiding their behavior towards practicing these activities and becoming convinced of them, as asserted by Al-Dahir (2018), Nagham (2012), and Bani Melhem \& Al-Wadian (2013). The researcher, throughout teaching the sports and health course, noticed a variation in the students' level and awareness of the scientific content offered for them in terms of the daily healthy habits; and in the eating behaviors and regular practice of the physical activities. Therefore, this study was conducted to identify the effect of teaching a sports and health course on certain trends of the students of this course in the Hashemite University. The Prior knowledge of the change in the students' trends towards teaching this course helps in increasing the effectiveness of the program, on the one hand, and assisting in improving their academic level, on the other. In addition, it may be a motive for the students to practice these healthy and eating habits, and urge them to practice the physical activities regularly, and enjoy a better healthy life.

\section{Objectives}

The study aimed to identify the effect of a sports and health course on the Hashemite University students' attitudes towards certain healthy eating habits and physical activities practice.

\subsection{Questions}

1. Are there statistically significant differences between the means of the pretest and posttest in the students' trends towards the healthy eating habits and physical activities practice?

2. Are there statistically significant differences between the means of the pretest and posttest in the students' trends towards the healthy eating habits and physical activities practice, ascribed to the (gender, college, academic year) variables?

\section{Procedures}

\subsection{Methodology}

The researcher employed the survey descriptive method due its suitability to the nature and objectives of this research. The study population consisted of the sports and health course male and female students in the Hashemite University $(n=300)$ in the first semester of the academic year 2020/2021. The sample comprised (100) male and female students (33\% of the study population), who were chosen by the stratified random method.

\subsection{Variables}

The independent variables are: gender (male, female), major (humane studies colleges, science colleges), and academic year (first, second, third, fourth, and fifth). The dependent variables are: domains of healthy eating habits and physical activity practice.

\subsection{Instrument}

The researcher employed the questionnaire developed by Saleh and Al-Ahmadi (2016), which consisted of (40) items distributed over two domains: healthy eating habits and physical activities practice (2o items each). The total reliability coefficient amounted (o.91). 


\subsection{Statistical Processing}

Data analysis was done using SPSS, means, standard deviations, and Relative Importance Index. TTest and the one-way analysis of variance (ANOVA) test were used to identify the differences between the means, as well as Scheffe' test that is used for the post hoc comparisons.

\section{Results}

Results of Question One: Are there statistically significant differences between the means of the pretest and posttest in the students' trends towards the healthy eating habits and physical activities practice? To answer this question, the M's and SD's were calculated for the domain and the instrument, as a whole, in both the pretest and posttest, in the students' trends towards the healthy eating habits and physical activity practice, as illustrated in Table (1).

Table 1: M's and SD's of the Domain and the Instrument, as a Whole, in the Pretest and Posttest in the Students' Trends towards Healthy Eating Habits and Physical Activities Practice

\begin{tabular}{|c|c|c|c|c|c|c|c|}
\hline \multirow{2}{*}{ Domain } & \multirow{2}{*}{ Test } & \multicolumn{2}{|c|}{ Level of Values } & \multirow[t]{2}{*}{$\mathrm{M}$} & \multirow[t]{2}{*}{ SD } & \multirow[t]{2}{*}{$\mathrm{T}$} & \multirow[t]{2}{*}{ Sign. } \\
\hline & & Highest Value & Lowest Value & & & & \\
\hline \multirow{2}{*}{ Healthy Eating Habits } & Pretest & 2.10 & 1.10 & 1.81 & 0.15 & \multirow{2}{*}{3.22} & \multirow{2}{*}{.0020} \\
\hline & Posttest & 2.10 & 1.55 & 1.86 & 0.12 & & \\
\hline \multirow{2}{*}{ Physical Activities Practice } & Pretest & 2.30 & 1.20 & 1.44 & 0.15 & \multirow[b]{2}{*}{$19 \cdot 51$} & \multirow{2}{*}{0.001} \\
\hline & Posttest & 1.75 & 1.10 & 1.81 & 0.12 & & \\
\hline \multirow{2}{*}{ Overall } & Pretest & 2.10 & 1.40 & 1.63 & 0.12 & \multirow{2}{*}{14.54} & \multirow{2}{*}{0.001} \\
\hline & Posttest & 1.80 & 1.33 & 1.84 & 0.08 & & \\
\hline
\end{tabular}

Table (1) shows that the mean in the pretest of the healthy eating habits domain amounted (o.81), while, in the posttest, it amounted (1.86). T-value amounted (3.22) with (.002) significance level, which is less than (0.05). This indicates statistically significant differences between the pre and posttests in this domain, in favor of the posttest. The mean of the pretest of the physical activities practice domain was (1.44), while it amounted (1.81) in the posttest. T-value was (19.51) with (.oo1) significance level, which is less than (0.05), indicating statistically significant differences between the pre and post-tests in this domain, in favor of the posttest. As for the overall domain, the means were (1.63) and (1.84) in the pretest and posttest, respectively. T-value was (14.54) with (o.0o1) significance level, i.e. less than (0.05), indicating statistically significant differences between the pre and post-tests in this domain, in favor of the posttest.

Results of Question Two: Are there statistically significant differences between the means of the pretest and posttest in the students' trends towards the healthy eating habits and physical activities practice, ascribed to the (gender, college, academic year) variables? To answer this question, the means, standard deviations of the domains and the instrument, as a whole, were calculated, according to the (gender, college and academic year) variables, as illustrated in Tables (2, 3 and 4 ).

Table 2: M's and SD's of the Domains and the Instrument, as a Whole, According to the Gender Variable

\begin{tabular}{|l|l|l|l|l|l|}
\hline \multirow{2}{*}{ Domains } & \multirow{2}{*}{ Variables } & \multicolumn{2}{l|}{ Pre-test } & \multicolumn{2}{l|}{ Post-test } \\
\cline { 3 - 7 } & & $\mathrm{M}$ & $\mathrm{SD}$ & $\mathrm{M}$ & $\mathrm{SD}$ \\
\hline \multirow{2}{*}{ Healthy Eating Habits } & Male & 1.83 & 0.15 & 1.87 & 0.12 \\
\cline { 2 - 6 } & Female & 1.79 & 0.15 & 1.86 & 0.10 \\
\hline \multirow{2}{*}{ Physical Activities Practice } & Male & 1.45 & 0.16 & 1.81 & 0.13 \\
\cline { 2 - 6 } & Female & 1.44 & 0.13 & 1.81 & 0.11 \\
\hline \multirow{2}{*}{ Overall } & Male & 1.62 & 0.12 & 1.84 & 0.10 \\
\cline { 2 - 6 } & Female & 1.64 & 0.11 & 1.84 & 0.10 \\
\hline
\end{tabular}


Table (2) shows the means and standard deviation of the healthy eating habits domain according to the (gender) variable. The pretest $M$ of the females was (1.83) and (1.79) for males; and for the posttest, the means were (1.87) and (1.43) for the females and males, respectively. As for the M's of the physical activities practice domain, according to the (gender) variable, the pretest M was (1.45) for females and (1.44) for the males. On the other hand, they were (1.81) and (1.81) for females and males on the posttest, respectively. Finally, the M's of the overall domain, according to the (gender) variable, were (1.62) and (1.64) for females and males, in the pretest, respectively; and, (1.84) and (1.84) for females and males, in the posttest, respectively.

Table 3: M's and SD's of the Domains and the Instrument, as a Whole, According to the College Variable

\begin{tabular}{|l|l|l|l|l|c|}
\hline \multirow{2}{*}{ Domains } & \multirow{2}{*}{ Variables } & \multicolumn{2}{|c|}{ Pre-test } & \multicolumn{2}{|c|}{ Post-test } \\
\cline { 3 - 7 } & & $\mathrm{M}$ & $\mathrm{SD}$ & \multicolumn{1}{c|}{$\mathrm{M}$} & \multicolumn{2}{|c|}{ SD } \\
\hline \multirow{2}{*}{ Healthy Eating Habits } & Humane & 1.83 & 0.12 & 1.89 & 0.12 \\
\cline { 2 - 7 } & Scientific & 1.80 & 0.17 & 1.85 & 0.11 \\
\hline \multirow{2}{*}{ Physical Activities Practice } & Humane & 1.43 & 0.14 & 1.81 & 0.12 \\
\cline { 2 - 7 } & Scientific & 1.45 & 0.15 & 1.81 & 0.12 \\
\hline \multirow{2}{*}{ Overall } & Humane & 1.62 & 0.10 & 1.85 & 0.08 \\
\cline { 2 - 7 } & Scientific & 1.63 & 0.12 & 1.83 & 0.08 \\
\hline
\end{tabular}

Table (3) shows the M's and SD's of the healthy eating habits domain according to the (college) variable. The $\mathrm{M}$ of the pretest for the humane colleges was (1.83), and (1.80) for the scientific colleges; and the M's of the posttest for the humane and scientific colleges were (1.89) and (1.85), respectively. As for the physical activities practice domain, the $\mathrm{M}$ of the pretest for the humane colleges was (1.43), and (1.45) for the scientific colleges according to the (college) variable. In the posttest of the humane colleges, the M was (1.81), and (1.81) for the scientific colleges. Finally, the M's of the pretest for the overall domain, according to the (college) variable, were (1.62) and (1.63), for the humane colleges and scientific colleges, respectively. In the posttest, the M's were (1.85) and (1.83) for the humane and scientific colleges, respectively.

Table 4: M's and SD's of the Domains and the Instrument, as a Whole, According to the Academic Year Variable

\begin{tabular}{|c|c|c|c|c|c|}
\hline \multirow{2}{*}{ Domains } & \multirow{2}{*}{ Variables } & \multicolumn{2}{|c|}{ Pre-test } & \multicolumn{2}{|c|}{ Post-test } \\
\hline & & $\mathrm{M}$ & $\mathrm{SD}$ & $\mathrm{M}$ & $\mathrm{SD}$ \\
\hline \multirow{5}{*}{ Healthy Eating Habits } & First Year & 1.83 & 0.12 & 1.86 & 0.122 \\
\hline & Second Year & 1.79 & 0.20 & 1.83 & 0.12 \\
\hline & Third Year & 1.81 & 0.13 & 1.88 & 0.12 \\
\hline & Fourth Year & 1.82 & 0.17 & 1.92 & 0.10 \\
\hline & Fifth Year & 1.79 & 0.21 & 1.84 & 0.10 \\
\hline \multirow{5}{*}{ Physical Activities Practice } & First Year & 1.38 & 0.22 & 1.79 & 0.11 \\
\hline & Second Year & 1.47 & 0.14 & 1.81 & 0.11 \\
\hline & Third Year & 1.50 & 0.10 & 1.80 & 0.12 \\
\hline & Fourth Year & 1.43 & 0.11 & 1.87 & 0.09 \\
\hline & Fifth Year & 1.44 & 0.10 & 1.80 & 0.10 \\
\hline \multirow{5}{*}{ Overall } & First Year & 1.82 & 0.12 & 1.82 & 0.12 \\
\hline & Second Year & 1.80 & 0.14 & 1.82 & 0.11 \\
\hline & Third Year & 1.43 & 0.17 & 1.84 & 0.17 \\
\hline & Fourth Year & 1.45 & 0.17 & 1.89 & 0.12 \\
\hline & Fifth Year & 1.62 & 0.13 & 1.82 & 0.08 \\
\hline
\end{tabular}


Table (4) illustrates the M's and SD's of the healthy eating habits domain, according to the academic year variable. The pretest M's for the healthy eating habits were: (1.83), (1.79), (1.81), (1.82) and (1.82) for the $1^{\text {st }}, 2^{\text {nd }}, 3^{\text {rd }}, 4^{\text {th }}$ and $5^{\text {th }}$ years, respectively. The posttest M's for this domain were: (1.86), (1.83), (1.88), (1.92), and (1.84) for the $1^{\text {st }}, 2^{\text {nd }}, 3^{\text {rd }}, 4^{\text {th }}$ and $5^{\text {th }}$ years, respectively. The Table also shows the M's and SD's of the physical activities practice domain, according to the academic year variable. The M's of the pretest of this domain were: $(1.38),(1.47),(1.50),(1.43)$, and $(1.44)$ for the $1^{\text {st }}, 2^{\text {nd }}, 3^{\text {rd }}, 4^{\text {th }}$, and $5^{\text {th }}$ years, respectively. As for the posttest of the physical activities practice domain, the M's were: (1.80), (1.83), (1.89, (1.92), and (1.87) for the $1^{\text {st }} .2^{\text {nd }}, 3^{\text {rd }}, 4^{\text {th }}$, and $5^{\text {th }}$ years, respectively. The M's of the pretest of domains and the instrument, as a whole, according to the (academic year) variable, were: (1.82), (1.80), (1.43), (1.45), and (1.62) for the $1^{\text {st }}, 2^{\text {nd }}, 3^{\text {rd }}, 4^{\text {th }}$, and $5^{\text {th }}$ years, respectively. For the posttest they were: (1.83), (1.82), (1.84), (1.89), and (1.89), for the $1^{\text {st }}, 2^{\text {nd }}, 3^{\text {rd }}, 4^{\text {th }}$, and $5^{\text {th }}$ years, respectively.

Tables (2, 3, and 4) show differences among the means of the study domains and the instrument, as a whole, ascribed to the gender, college and academic year variables. To define whether there are statistically significant differences at $(0.05 \geq P)$ level among the M's, the researcher applied the multiple analysis of variance procedures (MANOVA), as shown in Table (5).

Table 5: Results of the MANOVA for the Effect of the Independent Variables (Gender, College, Academic Year) on the Domains and the Instrument, As a Whole, in the Posttest

\begin{tabular}{|l|l|c|c|c|c|}
\hline Source & Domains & Total Squares & Squares Mean & F Value & Sign. \\
\hline \multirow{4}{*}{ Gender } & Healthy Eating Habits & 0.06 & 0.06 & 4.75 & 0.062 \\
\cline { 2 - 6 } & Physical Activities Practice & 0.00 & 0.00 & 0.06 & 0.806 \\
\cline { 2 - 6 } & Overall & 0.01 & 0.01 & 2.04 & 0.156 \\
\hline \multirow{4}{*}{ College } & Healthy Eating Habits & 0.01 & 0.01 & 0.68 & 0.412 \\
\cline { 2 - 6 } & Physical Activities Practice & 0.00 & 0.00 & 0.05 & 0.819 \\
\cline { 2 - 6 } & Overall & 0.00 & 0.00 & 0.19 & 0.661 \\
\hline \multirow{3}{*}{ Academic Year } & Healthy Eating Habits & 0.02 & 0.00 & 0.31 & 0.872 \\
\cline { 2 - 6 } & Physical Activities Practice & 0.19 & 0.05 & 3.68 & 0.008 \\
\cline { 2 - 6 } & Overall & 0.04 & 0.01 & 1.50 & 0.209 \\
\hline \multirow{5}{*}{ Error } & Healthy Eating Habits & 1.18 & 0.01 & & \\
\hline & Physical Activities Practice & 1.15 & 0.01 & & \\
\cline { 2 - 6 } & Overall & 0.54 & 0.01 & & \\
\hline \multirow{3}{*}{ Overall } & Healthy Eating Habits & 322.05 & & & \\
\cline { 2 - 7 } & Physical Activities Practice & 205.17 & & & \\
\cline { 2 - 6 } & Overall & 259.53 & & & \\
\hline
\end{tabular}

Table (5) shows that there are no statistically significant differences in all the domains and the instrument, as a whole, ascribed to the gender and college variables. Furthermore, there are no statistically significant differences in the healthy eating habits domain and the instrument, as a whole, ascribed to the academic year variable. Meanwhile, the table shows statistically significant differences in the physical activities practice domain ascribed to the academic year variable. To determine the academic year to which these differences are in favor, Scheffe Test for post hoc comparisons was used, as shown in Table (6).

Table 6: Results of Scheffe Test Analysis of the Effect of the Academic Year on the Physical Activities Practice Domain

\begin{tabular}{|l|l|l|c|c|c|}
\hline Independent Variables & \multicolumn{2}{|l|}{ Totals } & Differences Mean & Standard Error & Sig. \\
\hline \multirow{4}{*}{ Physical Activities Practice } & Firs Year & Second Year & -0.09 & 0.03 & 0.117 \\
\cline { 2 - 6 } & First Year & Third Year & $-0.12^{*}$ & 0.03 & 0.009 \\
\cline { 2 - 6 } & First Year & Fourth Year & -0.04 & 0.04 & 0.891 \\
\cline { 2 - 6 } & First Year & Fifth Year & -0.06 & 0.04 & 0.703 \\
\hline
\end{tabular}




\begin{tabular}{|l|l|l|c|c|c|}
\hline Independent Variables & \multicolumn{2}{|l|}{ Totals } & Differences Mean & Standard Error & Sig. \\
\hline \multirow{4}{*}{} & Second Year & Third Year & -0.03 & 0.03 & 0.925 \\
\cline { 2 - 6 } & Second Year & Fourth Year & 0.05 & 0.04 & 0.762 \\
\cline { 2 - 6 } & Second Year & Fifth Year & 0.03 & 0.04 & 0.981 \\
\cline { 2 - 6 } & Third Year & Fourth Year & 0.08 & 0.04 & 0.304 \\
\cline { 2 - 6 } & Third Year & Fifth Year & 0.06 & 0.04 & 0.753 \\
\cline { 2 - 6 } & Fourth Year & Fifth Year & -0.02 & 0.05 & 0.992 \\
\hline
\end{tabular}

Table (6) clearly shows statistically significant differences between the first and third academic year group, in favor of the first, because the significance level is (o.009), which is less than (0.05) level. Meanwhile, there were no differences among the other academic year's groups, because the actual significance level is higher than (0.05).

\section{Discussion}

The results showed statistically significant differences between the pre and post-tests in all the domains, in favor of the posttest. The researcher ascribes them to the degree of the student's benefits of the sports and health course content, which was reflected in the individual's behavior. It is also ascribed to an increase in the health culture, healthy eating habits, and physical activities practice

These results are in line with those of Marwa's study (2019), which showed that the level of the health culture increased by $(70 \%)$ among the female students who practiced physical activities, as compared to those who did not. Our results are also in line with the study of Zubaidi and Farahat (2020) that the female students' trends towards practicing physical activities were positive. However, our study is not in line with the study of Yahia et al, (2016) and Al-Qass (2016). Their results concerning the students' habits, their nutrition knowledge, physical activity and life style indicated that most of the students were not physically active; only $7 \%$ of the university students enjoy an active life style, and only $4 \%$ have good eating knowledge. Their study further showed that there was no positive effect of the academic curriculum of the health and active practice on the school students. Our study was also not in line with that of Ashkanani \& Al Dwairji (2021), which showed that the level of general eating knowledge among the students enrolled in the Basic Education College in Kuwait was poor.

The results also showed differences in the means in all the domains and the instrument, as a whole, between the pre and post-tests ascribed to the gender variable, in favor of the females in the healthy eating habits domain. This is attributed to that the female, for the social roles she is required to perform in the family, became more interested in eating habits, and more knowledgeable of the information and healthy eating habits, as compared to the males. This is in line with the study of AlDoori (2017), Al-Asa (2013), and Arjan et al (2013), which showed that the females were of higher health awareness level. In addition, the study of Andonova (2018) showed that the female students were familiar with the basic principles of the healthy nutrition. As for the domain of physical activities practice, it was in favor of the males. This is imputed to that they have more freedom in motions and practicing physical activities, as compared to their female peers; and also ascribed to that the environment has a role in this concern. This result is in line with that of Al-Jafri (2014) in that the male students are more positive than the female in practicing physical activities. Our results are not in line with those of the study of Al-Mulla (2006), which indicated statistically significant differences in changing the trends of the students towards practice of the physical activities, which were in favor of the female students. On the other hand, our results were not in line with the study of Al-Atrash (2016) and Zayed et al (2004), which indicated that there are no statistically significant differences among the two genders on the change scale in the level of the trends towards practicing sports activity, after studying the course. They also indicated that there is a wide agreement between the trends of both genders towards the sports activity, which could be explained by that the importance of sports rises equally with both genders. 
The results also showed differences in the M's in all domains and the instrument, as a whole, between the pretest and posttest that are attributed to the college variable, in favor of the humane colleges. This is due to that the humane colleges' students have less credit hours than the scientific colleges in their study plans, which cause a lesser study pressure. Consequently, offering the possibility of practicing more physical activities than students of the scientific colleges. This is in line with the studies of Al-Atrash (2016), Saleh and Al-Ahmadi (2016), and Hami (2016). They indicated the presence of the sports concepts, facts and knowledge that are related to the effect of the sports activity on the different aspects of the individual (health, social, psychological and scientific), which the students received in the sports and health course. Such information may not be equally needed by both the scientific and humane courses students. Meanwhile, the study of Nashmi and Tareq (2010) revealed that there are no statistically significant differences between the scientific and humane colleges' students, who practiced sports activity, in all the activity dimensions.

Our results further showed differences in the means of all domains, and the instrument, as a whole, between the pre and post-tests, attributed to the academic year, which was in favor of the first year in the physical activities practice domain. Our results are in line with those of Hami (2016) that the first stages of the university student have less credit hours than other stages, with less difficulty of the major courses as well. In addition, it may be ascribed to the age and higher motivation levels than students of other years. Meanwhile, the results of our study were not in line with the study of Arjan et al (2013), which indicated statistically significant differences in the health awareness level, in favor of the fourth year students. On the other hand, Al-Mulla's study (2006) indicated that there were no statistically significant differences in changing students' attitudes towards physical activities ascribed to the academic year variable.

\section{Conclusions}

- The students benefited the sports and health course content, which reflected in a behavior that the individual practices.

- The health culture, healthy eating habits, and physical activities practice increased with the students.

- The health culture level increased with the female students to practice physical activity.

- The female students' trends towards sports activities practice were positive.

\section{Recommendations}

- Maintaining the sports and health course as a requirement for all the disciplines in the University.

- There is a need for ongoing development of the scientific content of the sports and health course, and adding the latest health developments to it.

- It is necessary to develop the teaching method of the sports and health course, so that it includes both the theoretical and practical sides, instead of restricting it to the theoretical only.

- Activation of the role of the studies, consultations and community service center in the University in spreading the nutritious and sports culture for the university students and the local community.

\section{References}

Al-Asa, A. (2013). Eating habits and physical activity among the school students in Bethlehem Governorate. Unpublished MA thesis, Al-Quds University, Palestine. 
Al-Atrash, M. H. (2016). Measuring the change in the level of attitudes towards sports activity practice after studying the fitness course at An-Najah National University, Derasat: Educational Sciences, 43(3), $1145-1422$.

Al-Dahri, S. H. (2018). Basics of health, neuropsychology, and behavioral therapy - bases and theories. Amman, Jordan, Dar Safa'a for Printing, Publication and Distribution.

Al-Doory, Q. M. (2017). Art of the healthy behavior and primary prevention. Amman, Dar Al-Hamid for Publication and Distribution.

Al-Jabali, H. (2018). Health Culture, Amman, Dar Osama for Publishing and Distribution.

Al-Jafri, A. (2014). Trends of King Abdul Aziz University students in Saudi Arabia towards the physical activity practice, An-Najah National University Journal for Research (Humane Sciences), 28(4), 1899-1922.

Al-Khaffaf, N. K. N. (2012). Trends of the female students of certain colleges of Mosul University towards practicing indoor Futsal (football) sport, Rafidain Journal for Sports Sciences, 8(59), 55-68.

Al-Mulla, F. H. (2006). Effect of teaching health and sports course on changing the trends of the Faculty of Education students in Bahrain University towards the physical activity, Arabian Gulf Mission, 27(102), 15-42. DOI10.35270/o011-027-102-001.

Al-Qass, S. (2016). Effectiveness of a health education program in changing the dangerous behaviors, and developing the health awareness among the adolescents. Unpublished PhD dissertation, Mohamed Khider University- Biskra, Algeria.

Al-Samadi, A. A. \& Al-Harithi, I. A. (2017). Level of the healthy behavior among Umm Al Qura University students, Kuwait, Educational Journal, 31(122). 125-145.

Al-Shafie, A. M. (2010). Evaluative study of the healthy behavior of the gifted students' school. MA Thesis, Faculty of Education, Zagazig University, Egypt.

Al-Zo'bi, S.; Al-Alwan, B.; \& Al-Nader, H. (2020). Effect of teaching the sports course for everybody in deepening the sports awareness with a sample of Balqa Applied University students, Sports Sciences Application Journal, 6(104), 193-209. DOI: .10.21608/jaar.2020.88985.

Andonova. A. (2018). The Nutritional Habits of Female Students Aged 18 to 25, Trakia Journal of Sciences,16(1), 235240. DOI:10.15547/tjs.s.01.047.

Arjan, J.; Theeb, M.; \& Al-Kilani, G. (2013). Level of the health awareness and sources for obtaining the health information among Balqa Applied University students in Jordan, Journal of Educational and Psychological Sciences, 1(14), 311-344.

Ashkanani, F. \& Al Dwairji, M. A. (2021). Nutrition Knowledge among College of Basic Education Students in Kuwait: A Cross-Sectional Study, Journal of Nutrition and Metabolism. ID 5560714, 12 pages. DOI.org/10.1155/2021/5560714.

Bani Melhem, M. \& Al-Wadian, H. (2013). Daily eating habits and behaviors among the Faculty of Sports Education in Al-Yarmouk University, Mutah Journal for Research and Studies, Humane and Social Sciences Serials, 28(6), 179-201.

Hami, A. Q. (2016). Effectiveness of using the guided discovery method in developing the students' trends towards the sports, Zakho University Journal, 4(1), 152-166.

Jwaihan, M. \& Arjan, J. (2018). Effect of a computer-based educational program on developing the health and health awareness related physical fitness among a sample of Balqa' Applied University students, Derasat Journal: Educational Sciences, 4(1), 1-24.

Koehler, K. \& Drenowatz, C. (2019). Integrated Role of Nutrition and Physical Activity for Lifelong Health, Journal List Nutrients, 11(7), 1437.

Maghaireh, E. \& Ahmad, B. (2011). Effect of teaching the sports course for all in the trends of Balqa' Applied University students/Zarqa University College towards the sports activity practice, Derasat Journal: Educational Sciences, 38(2), 2369-2383. DOI: 10.35516/0102-038-002-011

Marwa, M. (2019). Health culture and its relationship to the healthy behavior of the female students who practice and who do not practice physical activity in Assiut University, Scientific Journal for Physical Education and Sports Science, 86(1), 1-29.

Masha'al, M., Al-Rahahleh, W., \& Bataieh, M. (2012). The cognitive outcome of nutritional culture and the level of aerobic fitness among students of the Faculty of Physical Education at the University, Derasat: Educational Sciences, 39(2), 380-393.

Ministry of Health, Jordan (2019). Studies and Information Department/ Institutional Development and Quality Control Directorate.

Nashmi, A. \& Tareq, A. (2010). Comparison between the students of the scientific and humane colleges in AlMuthanna University towards sports activity practice, Al-Qadisiah Journal for Sports Education Sciences, 10(3), 109-124. 
Ruiz, M. A., Martinez, M. \& Gladys, M. M. (2017). Inquiring Sport and Physical Activity students' perceptions using metaphors as research tools, Journal Retos, 32, 119-123.

Saleh, S. F. A. \& Al-Ahmadi, S. A. (2016). Effect of health and fitness programs teaching on certain trends of the students of the preparatory academic year in Ha'il University, Faculty of Education Journal, Al-Azhar University, 35(170), part (2), 132-169.

Sofi, F., Andrea, C., Francesca C., Rosanna, A. \& Bbate, G. (20o8). Physical activity during leisure time and primary prevention of coronary heart disease: an updated meta- analysis of cohort studies, European Journal of Cardiovascular Prevention \& Rehabilitation, 15(3), 247-257. PMID: 18525378 DOI: 10.1097/HJR.obo13e3282f232ac.

Sogari, G., Argumedo, C. V., Gómez, M. \& Mora, C. (2018). College Students and Eating Habits: A Study Using an Ecological Model for Healthy Behavior, Journal List Nutrients, 10(12); 1823. DOI: 10.339o/nu10121823.

Yahia, N., Wang, D., Rabley, M. \& Dey, R. (2016). Assessment of weight status, dietary habits and beliefs, physical activity, and nutritional knowledge among university students, Perspect Public Health (PMID), 136(4), 231244. DOI: 10.1177/1757913915609945.

Yalcin, I., Araz, G. Y., Ekinci, N. E. \& Birkok, M. C. (2020). The Effect of Sports Attitude on Healthy Lifestyle Behavior in University Students, Progress in Nutrition, 22(1), 66-71. DOI: 10.23751/pn. v22i1-S.9786.

Zayed, K., Al-Jabali, M. \& Al-Shaili, A. (2004). Trends of Sultan Qaboos University students towards the sports activity and their relationship with certain variables, Psychoeducational Studies Journal, Sultan Qaboos University, 8(7), 47-76.

Zubaidi, F. M. N. \& Farahat, R. M. S. (2020). Trends of the students of Palestine Technical University, Kadoorie, Ramallah Branch, towards sport activities practice, Palestine Technical University Journal for Research, 8(1), 65-75. 